\title{
Prevalence of Premenstrual Syndrome and its Effects among Regular Female Students in Ambo University, West Shoa, Oromia Regional State, Ethiopia, 2019
}

\author{
Teferra Likasa ${ }^{1}$, and Takele Tiki ${ }^{2, *}$ \\ ${ }^{1}$ Department of Nursing, College of Medicine and Health Science, Ambo University, Ethiopia \\ ${ }^{2}$ Department of Psychiatry Nursing, College of Medicine and Health Science, Ambo University, Ethiopia
}

*Corresponding author: Takele Tiki, Department of Psychiatric Nursing, College of Medicine and Health Science, Ambo University, Ethiopia, Tel: +25112208967; E-mail: takesibirat14@gmail.com

Received: 07 Jul, 2019 | Accepted: 29 Jul, 2019 | Published: 08 Aug, 2019

Citation: Likasa T, Tiki T (2019) Prevalence of Premenstrual Syndrome and its Effects among Regular Female Students in Ambo University, West Shoa, Oromia Regional State, Ethiopia, 2019. J Psychiatry Ment Health 4(2): dx.doi.org/10.16966/2474-7769.132

Copyright: (c) 2019 Likasa T, et al. This is an open-access article distributed under the terms of the Creative Commons Attribution License, which permits unrestricted use, distribution, and reproduction in any medium, provided the original author and source are credited.

\begin{abstract}
Background: Premenstrual Syndrome (PMS), also known as premenstrual tension is defined as a complex of emotional, physical and behavioral symptoms that start at the last week of a woman's reproductive cycle and end with the onset of menstruation.

Objective: The objective of the study was to assess the prevalence of premenstrual syndrome and its effects among female students in Ambo University, west shoa, Oromia regional state, Ethiopia, 2019.

Method: Institutional based descriptive cross sectional study was conducted from January 1-20, 2019 on all female students in Ambo University. The sample size was determined using single population proportion formula and 288 study subjects were selected. The study subject was selected using systematic random sampling. Data was analyzed using SPSS version 20.

Results: Of the 288 female students, all responded to the questions $100 \%$. The results of the study show that the prevalence of PMS was found to be $51(18 \%)$. Out of the female students diagnosed with PMS, $75 \%$ had stopped studying and class missing was reported by $40 \%$ of the students.

Conclusion and Recommendation: The study concludes among 288 chosen samples regarding the prevalence of PMS among female students in Ambo University main campus and effects related to PMS. Although a full grasp of the concept of PMS in Ambo University has not been covered, this study revealed that Ambo University female students have symptoms similar to other area in Ethiopia and some report so severe symptoms that they interfere with daily functioning. Therefore, awareness about PMS appropriate medical treatment and psychotherapy services should be provided to affected female students.
\end{abstract}

Keywords: Premenstrual syndrome; Female students; Ambo University; Central Ethiopia

\section{Background}

Premenstrual syndrome (PMS), also known as premenstrual tension is defined as a complex of emotional, physical and behavioral symptoms that start at the last week of a woman's reproductive cycle and ends with the onset of menstruation [1]. PMS should not be confused with the regular pain of menstruation because physiologic pain during menstruation uniquely resolves with the onset of a woman's period. The most common behavioral symptoms are anxiety, depression, irritability, mood swings, angry outbursts, confusion, changes in appetite, decreased concentration, withdrawal from social activities and inability to cope with daily activities, while the most frequent somatic symptoms include abdominal bloating, breast tenderness, body aches, back pain, upper thigh pain, headache, fatigue and swelling of extremities, where psychological symptoms like school/work absenteeism [2-4].

Premenstrual symptoms might cause several difficulties for female including impairment in physical functioning, psychological health, and severe dysfunction in social or occupational functioning. In young adolescents, symptoms might particularly affect school functions and social interactions in a negative way [5-8]. The overall prevalence reported varies between $30-90 \%$, with $5-10 \%$ reporting severe symptoms [9-11]. Whatever the cause(s) of PMS, it is clear that the complaints are related to the changes in the hormonal milieu produced by the menstrual cycle, which is itself under the control of the hypothalamic-pituitary-ovarian axis [12]. 
The American Physician family report prevalence PMS 3-30\% [3], Iranian and Chinese 18-20\% [13,14], Asian 59\%, 53\% [15,16], UK from 75 to $85 \%$ [17], University Bangkok, 41\% [18], Jordan University About 22\% [19], Iranian Adolescents students, 31.4\% [20]. Isra University Hospital, Pakistan (51\%) [21], Yenişehir primary care center in Turkey, 79\% [22].

In our neighbor country Eritrea, the research conducted on prevalence and effects of PMS among female health science students reveals that the prevalence of PMS was $17.5 \%$ out of 240 students [23]. A research done in Addis ketema preparatory school, Addis Ababa Ethiopia shows that out of the sampled female students $41.3 \%$ [24], Jima University 99.6\% [8].

Therefore, this study aimed to determine the prevalence of Premenstrual syndrome and effects on female students of Ambo University health science students. In addition, examine the phenomenon of unreported and under reported premenstrual syndrome female students that is virtually hidden.

\section{Method}

Institutional based descriptive cross-sectional study was conducted from January 1 to 20, 2019 GC at Ambo University which was west shoa zone central Ethiopia. The sample size was calculated using single population proportion formula by assuming population proportion $33 \%$ [25]. To get the possible sample at 95\% confidence interval, which is $\mathrm{z}$-value of 1.96 and marginal error of $5 \%$, it is calculated as follows:

$$
\begin{aligned}
& n=\frac{z^{2} p(1-p)}{d^{2}} \\
& n=\frac{(1.96)^{2} \times 0.33 \times(1-0.33)}{(0.5)^{2}}=\frac{3.8416 \times 0.33 \times 0.67}{0.0025}=\frac{0.8493}{0.0025} \\
& n=340
\end{aligned}
$$

Where, $\mathrm{z}$ represents level of confidence interval (95\%); P represents population proportion; and $\mathrm{n}$ represents sample size.

Since our sample, $\mathrm{n}$ was less than 10,000; we used correction formula,

$$
n f=\frac{n}{1+\frac{n}{N}}
$$

Where, $\mathrm{N}$ represents total number of female students selected from colleges; $\mathrm{N}$ represents calculated sample size; $\mathrm{nf}$ represents required sample size to be selected in Ambo University.

By taking our source population $\mathrm{N}=1321$ (Total number of female students found in the three colleges, November 2018 EC).

$$
n f=\frac{n}{1+\frac{n}{N}}=\frac{340}{1+\frac{340}{1321}}=\frac{340}{1+0.3}=\frac{340}{1.3}=262
$$

By considering $10 \%$ non-response rate, $10 \%$ of $262=26$.

So, our final sample size will be $262+26=288$.

Sampling in Ambo University main campus, there are seven colleges. From those colleges, we selected three colleges by using simple random sampling. Systematic random sampling was employed to select and approach each study subjects. $K$ value $=\mathrm{N} / \mathrm{nf}$ where, $\mathrm{N}=$ total number of female students (1321).

$$
\mathrm{nf}=\text { Total sample size }(\text { required })=1321 / 288=5 \text {. }
$$

Ethical clearance was obtained from Ambo University research committee written informed consent for participation in the study was obtained from participants just after start of the interview.

\section{Results}

$100 \%$ response rate of participants. Among the respondents, $82(28 \%)$ were from medicine and health science college, $77(27 \%)$ were from business and economics college and $129(45 \%)$ were from college of natural and computational science. The prevalence of PMS among the participants was $18 \%$. It is calculated that $23(45 \%)$ of subjects with positive history stopped performing their usual activities (eating, washing, talking to friends). The respondents who qualified for the diagnosis of PMS considerably suffered on their academic as well as social lives. The most common academic performance impairment was cessation or interruption of studying which was reported by $38(75 \%)$ of those diagnosed with premenstrual syndrome. Our study finding showed that, the magnitude for severely depressed mood is $58(20.4 \%)$, for severely anxiety or tension is $37(12.8 \%)$, for markedly irritability is $29(10.1 \%)$, for headache is $71(24.7 \%)$, for fatigue is $59(20.5 \%)$, for severely breast tenderness is $49(17 \%)$, for severely backache is $60(20.8 \%)$, for marked menstrual cramp is $56(19.4 \%)$ and the magnitude of decreased interest in usual activities and social withdrawal is $45.3 \%, 68.5 \%$ for lack of energy, $49.2 \%$ for appetite change, $35.4 \%$ for change in sleep pattern, $21 \%$ for feeling of out of control or overwhelmed, $38.7 \%$ for difficulty of concentration and $41.4 \%$ and $37 \%$ for somatic symptoms such as abdominal bloating and symptoms severe enough to interfere with day to day activities respectively (Figure 1).

Majority of the respondent had their first menstrual flow between the ages of 13 to 16 years which was $65.5 \%$ and had menstrual cycles ranging from 21-35 days which was 55\% (Figure 2). All subjects responded about their ethnicity and 152 (53\%) were Oromo, 105(36.5\%) were Amara, 17(6\%) were Tigre and 14(5\%) were others (Table 1).

\section{Discussion}

This study had been attempted to determine the prevalence of premenstrual syndrome among Ambo University female students in main campus. Our findings show the magnitude of premenstrual syndrome was (18\%) almost similar with Eritrean 17.5 [23]. But other literatures reveal different findings with larger magnitude such as Guder, West Shoa, Oromia regional state, Ethiopia, 2017; Addis ketema, Addis Ababa and Jimma University, Ethiopia; Yenişehir primary care center in Turkey and Isra University Hospital, Pakistan which was (33.37\%), (30.4\%), (99.6\%), (79\%), (51\%) respectively $[8,21,22,24]$ and study conducted in Jordan University showed lesser magnitude than this study (9.6\%) [19].

According to an article written in Addis ketema $73.2 \%$ of the respondents have markedly depressed mood with feelings of hopelessness, $73.8 \%$ have decreased interest in usual activities and social withdrawal and $71.5 \%$ have somatic symptoms such as abdominal bloating. And a research done at Jimma University indicated that the magnitude of markedly depressed mood with feelings of hopelessness is $59.9 \%, 49.6 \%$ for irritability, $73.1 \%$ showed decreased interest in usual activities, and the magnitude of change in appetite and sleep pattern is $61.9 \%$ and $60.3 \%$ respectively. 


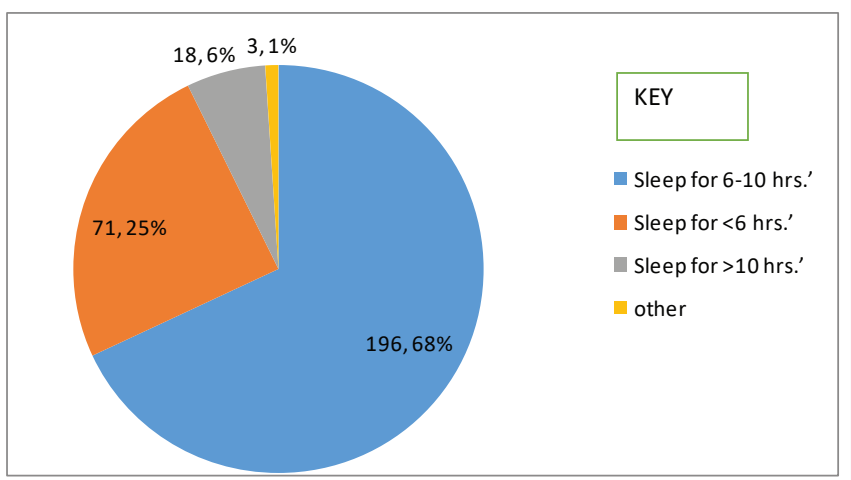

Figure 1: Sleep habit of the study subjects.

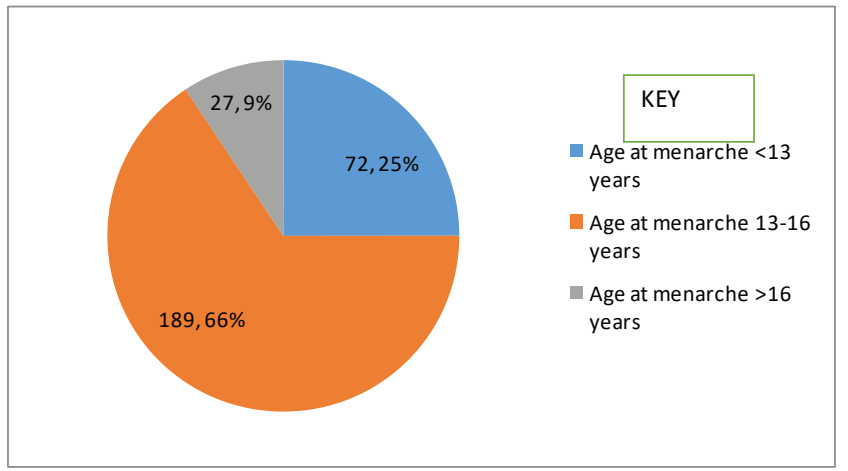

Figure 2: Age at menarche shown by pie chart.

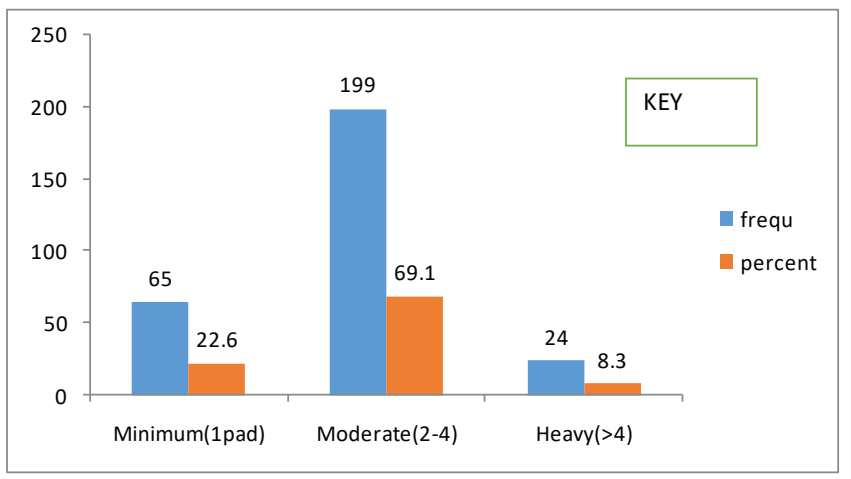

Figure 3: Severe of premenstrual syndrome flow shown by graph.

A research article which was done in Iranian adolescent students showed that $89.7 \%$ have abdominal bloating [20] and an article of Isra University Hospital, Pakistan indicated that $34.3 \%$ are with symptoms which are severe enough to interfere with day to day activities.

In thesis computed at Jordan University about $17 \%$ of the participants had menstrual cycle duration of less than five days while $83 \%$ of them had menstrual cycle durations of five days or more [19] (Figure 3).

According to our research, the duration of menstrual cycle is greater than 4 days for $99(34.4 \%)$ of the study subjects, 4 days for $142(49.3 \%)$ and less than 4 days for $47(16.3 \%)$ of the study subjects.
Table 1: Socio-demographic characteristics of respondents in Ambo University female regular students.

\begin{tabular}{|c|c|c|c|}
\hline Variables & Characteristics & Frequency & (\%) \\
\hline \multirow{3}{*}{ Age } & $<20$ & 110 & 38.2 \\
\hline & $20-23$ & 156 & 54.2 \\
\hline & $>24$ & 22 & 7.6 \\
\hline \multirow{4}{*}{ Religion } & Orthodox & 124 & 43.1 \\
\hline & Protestant & 131 & 45.5 \\
\hline & Muslim & 24 & 8.3 \\
\hline & Other & 9 & 3.1 \\
\hline \multirow{4}{*}{ Ethnicity } & Oromo & 152 & 53.0 \\
\hline & Amara & 105 & 36.5 \\
\hline & Tigre & 17 & 5.9 \\
\hline & Other & 14 & 4.9 \\
\hline \multirow{4}{*}{ Marital Status } & Single & 256 & 88.9 \\
\hline & Married & 32 & 11.1 \\
\hline & Divorced & 0 & 0 \\
\hline & Other & 0 & 0 \\
\hline \multirow{2}{*}{ Residence } & Urban & 172 & 59.7 \\
\hline & Rural & 116 & 40.3 \\
\hline \multirow{5}{*}{ Academic Year } & $1^{\text {st }}$ year & 58 & 20.1 \\
\hline & $2^{\text {nd }}$ year & 96 & 33.3 \\
\hline & $3^{\text {rd }}$ year & 117 & 40.6 \\
\hline & $4^{\text {th }}$ year & 14 & 4.9 \\
\hline & $5^{\text {th }}$ year & 3 & 1 \\
\hline \multirow{4}{*}{ Mothers Education } & No formal education & 113 & 39.2 \\
\hline & Primary school & 120 & 41.7 \\
\hline & High school & 25 & 8.7 \\
\hline & College/University & 30 & 10.4 \\
\hline \multirow{4}{*}{$\begin{array}{l}\text { Monthly Family } \\
\text { Income (Ethiopian } \\
\text { Birr) }\end{array}$} & $1000-3500$ & 123 & 42.7 \\
\hline & $3600-5000$ & 113 & 39.2 \\
\hline & $5100-10000$ & 26 & 9 \\
\hline & $>10000$ & 26 & 9 \\
\hline \multirow{4}{*}{ Family Status } & Family live together & 228 & 79.2 \\
\hline & Extended family & 31 & 10.8 \\
\hline & Divorced family & 27 & 9.4 \\
\hline & Other & 2 & 0.7 \\
\hline
\end{tabular}

The respondents who qualified for the diagnosis of PMS considerably suffered on their academic as well as social lives. The most common academic performance impairment was cessation or interruption of studying which was reported by $75 \%$ of those diagnosed with PMS. This contradicts with what was reported by the Eritrea who's highest scoring academic performance impairment was frequent class missing (90.5\%) [23].

$40 \%$ of those diagnosed with PMS in this study reported missing classes. This finding was inconsistent with the findings of Iranian studies, of which reported class missing rates was $25 \%$ [20]. The reasons on that made the percentage of this study to be higher might be due to the fact that the later studies analyzed performance impairment of the whole participants, not of the PMS affected ones only.

\section{Conclusion}

This study found out that only $9.5 \%$ of the PMS diagnosed students missed an exam. This finding is logically explainable as female students give priority and wouldn't want to miss their exams at any cost. 


\section{Declarations}

\section{Ethics approval and consent to participate}

The study proposal was initially approved by the ethical review board of Ambo University. A formal letter of permission was obtained from the college and submitted to department. The information about the study was given to the participants. Verbal and then written informed consent was sought from each participant who agreed to participate in the study and full filled the inclusions criteria. Only anonymous data collected in private rooms.

\section{Availability of data and materials}

This study is a part of institutional based descriptive cross sectional study among on female students. The dataset pertaining to this study will be shared upon reasonable request.

\section{Conflict of Interests}

The authors declare that they have no competing interests.

\section{Authors' Contributions}

Teferra L was involved in the conception, design, analysis, data interpretation and report writing. Takele $\mathrm{T}$ was involved in advice all part of activities. All of us have read and approved the final manuscript.

\section{Acknowledgements}

We would like to acknowledge Ambo University College of Medicine and Health Science for funding this study. In addition, we would like to thank data collectors and study participants.

\section{References}

1. Dennerstein L, Lehert P, Bäckström TC, Heinemann K (2009) Premenstrual symptoms-severity, duration and typology: an international cross-sectional study. Menopause Int 15: 120-126.

2. O'Brien PMS, Rapkin A, Schmidt PJ (2007) The Premenstrual Syndromes: PMS and PMDD. CRC Press, United States.

3. Biggs WS, Demuth RH (2011) Premenstrual Syndrome and Premenstrual Dysphoric Disorder. Am Fam Physician 84: 918-924.

4. Rapkin AJ, Winer SA (2009) Premenstrual syndrome and premenstrual dysphoric disorder: quality of life and burden of illness. Expert Rev Pharmacoecon Outcomes Res 9: 157-170.

5. Marván ML, Cortés-Iniestra S (2001) Women's beliefs about the prevalence of premenstrual syndrome and biases in recall of premenstrual changes. Health Psychol 20: 276-280.

6. Chia CF, Lai JH, Cheung PK, Kwong LT, Lau FP, et al. (2013) Dysmenorrhoea among Hong Kong university students: prevalence, impact, and management. Hong Kong Med J 19: 222-228.

7. Drosdzol A, Nowosielski K, Skrzypulec V, Plinta R (2011) Premenstrual disorders in Polish adolescent girls: prevalence and risk factors. $J$ Obstet Gynaecol Res 37: 1216-1221.

8. Tenkir A, Fisseha N, Ayele B (2003) Premenstrual syndrom: prevalence and effect on academic and social performances of students in Jimma University, Ethiopia. Ethiop J Health Dev 17: 181188
9. Wayne SM, Rosenwaks Z (1993) Dysmenorrhea and premenstrual syndrome (PMS). In: Copeland LJ (eds) Textbook of gynecology. Sounders, Philadelphia, United States 398-413.

10. O'Brien PM (1993) Helping women with premenstrual syndrome. BMJ 307: 1471-1475.

11. Johnson SR (1987) The epidemiology and social impact of premenstrual symptoms. Clin Obstet Gynecol 30: 367-376.

12. Levin O'Conner T, Barton JJ (1985) Comprehensive therapy. 225.

13. Chau JP, Chang AM, Chang AM (1998) Relationship between premenstrual tension syndrome and anxiety in Chinese adolescents. J Adolesc Health 22: 247-249.

14. Bakhshani NM, Mousavi MN, Khodabandeh G (2009) Prevalence and severity of premenstrual symptoms among Iranian female university students. J Pak Med Assoc 59: 205-208.

15. Anandha Lakshmi S, Priy M, Saraswathi I, Saravanan A, Ramamchandran C (2011) Prevalence of Premenstrual Syndrome and Dysmenorrhoea among Female Medical Students and its Association with College Absenteeism. Int J Biol Med Res 2: 10111016.

16. Mahesh A, Tirmizi ZA, Ali S (2011) Frequency and associated factors of premenstrual syndrome in medical college girls. Med Channel 17: 34-38.

17. Pérez-López FR, Chedraui P, Pérez-Roncero G, López-Baena MT, Cuadros-López JL (2009) Premenstrual Syndrome and Premenstrual Dysphoric Disorder: Symptoms and Cluster Influences. The Open Psychiatry Journal 3: 39-49.

18. Thu M, Diaz EO, Sawhsarkapaw (2006) Premenstrual Syndrome among Female University Students in Thailand. AU J T 9: 158-162.

19. Obeidat BA, Alchalabi HA, Abdul-Razzak KK, Al-Farras MI (2012) Premenstrual symptoms in dysmenorrheic college students: prevalence and relation to Vitamin $D$ and parathyroid hormone levels. Int J Environ Res Public Health 9: 4210-4222.

20. Delara M, Borzuei H, Montazeri A (2013) Premenstrual disorders: prevalence and associated factors in a sample of Iranian adolescents. Iran Red Crescent Med J 15: 695-700.

21. Nisar N, Zehra N, Haider G, Munir AA, Sohoo NA (2008) Frequency, intensity and impact of premenstrual syndrome in medical students. J Coll Physicians Surg Pak 18: 481-484.

22. Öztürk S, Tanrıverdi D, Erci B (2011) Premenstrual syndrome and management behaviours in Turkey. Aust J Adv Nurs 28: 54-60.

23. Azaria E, Mehari M, Kiros N, Woldu F, Tesfay A, et al. (2016) The Prevalence and Effects of Premenstrual Syndrome among Female Health Science Students in Eritrea. Eur J Clin Biomed Sci 2: 1-5.

24. Woldu M, Segni H, Gebremariam A (2014) Prevalence of premenstrual syndrome and associated functional disability among female students of Addis ketema preparatory school, Ethiopia. J Educ Res Beh Sci 3: 304-311.

25. Kelbessa B, Guteta B, Negese F, Badada B, Tujuba A, et al. (2017) Prevalence of Premenstrual Syndrome and Coping Mechanism among Female Students of Guder Preparatory School, West Shawa Zone, Oromia Regional State, Ethiopia. Res Rev J Med Health Sci 6: 12-19. 